\section{Clinical implications}

- The protozoan cryptosporidium causes severe diarrhoea in immunodeficient patients

- It is thought to cause only self limiting disease in immunocompetent people

- In this three year community study cryptosporidium was a common cause of persistent diarrhoea and death in otherwise healthy young children

- Prevention or effective treatment of cryptosporidiosis in infancy would reduce mortality in children aged 1-23 months by about $18 \%$

based data with a large number of relatively mild episodes of diarrhoea. A study of infants and young children admitted to hospital with severe diarrhoea would probably show a higher prevalence and mortality.

\section{CONCLUSIONS}

We conclude that cryptosporidiosis in infants in developing countries is not only a common cause of diarrhoea but a cause of excess mortality. Table II shows that in children with cryptosporidiosis in infancy $4 \cdot 3$ deaths $((36 \times 26 / 442)+(54 \times 19 / 463))$ could be expected in children aged 1-23 months. However, 16 deaths were recorded. Eradication of cryptosporidiosis in infancy by prevention and treatment should therefore theoretically reduce the 64 deaths reported in children aged 1-23 months by about $18 \%$ $(11 \cdot 7 / 64)$, assuming that the other factors affecting mortality are equally distributed among the exposed and non-exposed groups. This assumption is supported by the multivariate analysis.

Control of cryptosporidiosis should receive much more attention. Research is needed to improve the understanding of the natural course of the infection and the immunopathogenesis of the associated disease. Despite numerous attempts no consistently effective antiparasitic drug has been found and further research is urgently needed. Cryptosporidiosis can be prevented by measures such as improving domestic and personal hygiene, improving child feeding and lactation practices, and controlling zoonotic reservoirs and water supplies.
We thank Queba Djaná, Domingos Sanca, Mario Rui Lopes, Paulo Ubassé, Jean Gomes Sá, Faustino Umbunque, and Aquinaldo Djaná, for the field work, and Astrid Permin Lene Brink, and Uffe Gansted for their contributions. In particular, we wish to acknowledge Anja Vollmer and Henning Andersen, who died before publication of this study.

This work was supported by the Science and Technology for Development Programme of the European Commission (contract No TS2-0179); the University of Copenhagen, Denmark; the Danish Council for Development Research (grant Nos 104. Dan. 8/341 and 1114); the Danish Medical Research Council (grant Nos 12-6055 and 12-6967); and the Danchurchaid primary health care project in Guinea Bissau.

1 Current WL, Garcia LS. Cryptosporidiosis. Clin Microbiol Rev 1991;4:325-58. 2 Persistent diarrhoea in children in developing countries: memorandum from a WHO meeting. Bull World Health Organ 1988;66:709-17.

3 Sallon S, Deckelbaum RJ, Schmid II, Harlap S, Baras M, Spira DT Cryptosporidium, malnutrition, and chronic diarrhea in children. $A m \mathcal{f} D$ Child 1988;142:312-5.

4 Laxer MA, Alcantara AK, Javato-Laxer M, Menorca DM, Fernando MT, Ranoa CP. Immune response to cryptosporidiosis in Philippine children. Ranoa CP. Immune response to

5 Melbak K, Hejlyng $N$, Ingholt L, da Silva APJ, Jepsen S, Aaby P. An epidemic outbreak of cryptosporidiosis: a prospective community study from Guinea Bissau. Pediatr Infect Dis 7 1990;9:566-70.

6 Allen AVH, Ridley DS. Further observations on the formol-ether concentration technique for faecal parasites. F Clin Pathol 1970;23:545-6.

7 Henriksen SAa, Pohlenz JFL. Staining of cryptosporidia by a modified ZiehlNeelsen technique. Acta Vet Scand 1981;22:594-6.

8 Kleinbaum DG, Kupper LI, Morgenstern H. Epidemiologic research. New York: Van Nostrand Reinhold, 1982.

9 Mata L, Bolanos H, Pizarro D, Vives M. Cryptosporidiosis in children from some highland Costa Rican rural and urban areas. Am f Trop Med Hyg 1984;33:24-9.

10 Cross JH, Alcantara A, Alquiza L, Zaraspe G, Ranoa C. Cryptosporidiosis in Philippine children. Southeast Asian $\mathcal{F}$ Trop Med Public Health 1985;16: 257-60.

11 Højlyng N, Mølbak K, Jepsen S. Cryptosporidium spp, a frequent cause of diantoea in Liberian children.7 Clin Microbiol 1986;23:1109-13.

12 Pal S, Bhattacharya SK, Das P, Chaudhuri P, Dutta P, De SP, et al. Occurrence and significance of cryptosporidium infection in Calcutta. Trans R Soc Trop Med Hyg 1989; 83:520-1.

13 Fripp PJ, Bothma MT, Crewe-Brown HH. Four years of cryptosporidiosis a

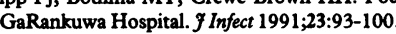

14 Poulsen A-G, Kvinesdal B, Aaby P, Melbak K, Frederiksen K, Dias F, et al Prevalence and mortality from human immunodeficiency virus type 2 in Bissau, West Africa. Lancet 1989;i:827-31.

15 Lisse IM, Whittle H, Aaby P, Normark M, Gyhrs A, Ryder L. Labelling of T cell subsets under field conditions in tropical countries. 7 Immunol Methods 1990;129:49-53.

16 Semba RD, Muhilal, Ward BJ, Griffin DE, Scott AL, Natadisastra G, et al Abnormal $T$ cell subset proportions in vitamin-A-deficient children. Lancet Abnormal T cell

17 Su S-X, Fang G-D, Fayer R, Guerrant RL. Cryptosporidiosis: pathogenesis and immunology. Parasitology Today 1992;8:24-7.

18 Argenzio RA, Liagos JA, Levy MI Meuten DJ, Lecce JG, Powell DW. Villous atrophy, crypt hyperplasia, cellular infiltration, and impaired glucose- $\mathrm{Na}$ absorption in enteric cryptosporidiosis of pigs. Gastroenterolog 1990;98:1129-40

(Accepred 3 Fune 1993)

\title{
Urinary microalbumin excretion in early pregnancy and gestational age at delivery
}

\author{
Ivan J Perry, Peter Gosling, K Sanghera, \\ David Churchill, D M Luesley, D G Beevers
}

Urinary microalbumin excretion in pregnancy may be an early marker for pre-eclampsia, although findings from small clinical studies are inconsistent. ${ }^{12}$ The relation between microalbumin excretion and other end points in pregnancy, such as gestational age at delivery, has not been considered. In a study that was primarily concerned with early markers for preeclampsia we examined the relation between microalbumin excretion in early pregnancy and gestational age at delivery.

Correspondence to: Dr Perry.

\section{Subjects, methods, and results}

We studied clinical and laboratory markers of preeclampsia in 692 healthy, nulliparous pregnant women referred for antenatal care before the 31 st week of gestation. Data on urinary microalbumin excretion at the first antenatal visit (median (interquartile range) gestation 16 (12-17) weeks) were available for 241 women. Urine samples (which were additional to samples obtained routinely) were not available for all women because of limited staff at some clinics and storage problems. The ethnic distribution of the 241 women reflected that the larger cohort of 692 women and that of nulliparous women referred to our unit. After the exclusion of women with essential hypertension, twin births, renal disease, and missing data on gestational age, 233 women were available for analysis.

Urinary albumin excretion rates were estimated from the albumin:creatinine ratio in random, "spot" urine samples taken after the women had sat for about one hour. ${ }^{3}$ The urine specimens were stored in glass containers, frozen at $-20^{\circ} \mathrm{C}$ on the day of sampling, and assayed within four to eight weeks. All specimens were submitted for analysis unless they were blood stained or greatly contaminated. The specimens were assayed by using a double antibody radioimmunoassay (Diagnostic Products Corporation, Wallingford, Oxfordshire).

Gestational age was estimated from the date of last 
Department of Public Health and Primary Care, Royal Free Hospital School of Medicine, London NW3 2PF

Ivan J Perry, lecturer in public health

Biochemistry Department, Selly Oak Hospital, Birmingham B29 6JD

Peter Gosling, chemical pathologist

K Sanghera, research fellow David Churchill, British Heart Foundation research fellow

University Departments of Medicine and Obstetrics, Dudley Road Hospital, Birmingham B18 7QH

D M Luesley, senior lecturer in obstetrics

D G Beevers, reader in medicine menstrual period and an ultrasound scan performed at the first antenatal visit. As the distribution of both the albumin:creatinine ratio and gestational age was skewed, each was transformed logarithmically (log albumin:creatinine and log (44-gestational age)) to produce normally distributed data for analysis.

The median gestational age at birth was 40 weeks, range 28-42 weeks. The albumin:creatinine ratio at the first visit (geometric mean (95\% range)) was significantly raised in women who had preterm birth $(\mathrm{n}=35 ; 0.84(0.2$ to 4.2$) \mathrm{mg} / \mathrm{mmol})$ compared with women who had term deliveries $(n=198 ; 0.57(0.1$ to $3.4) \mathrm{mg} / \mathrm{mmol} ; \mathrm{p}=0.02$ ). There was a significant inverse association between gestational age at delivery and first visit albumin:creatinine ratio $(r=-0 \cdot 15$, $p=0.03$ ). This association was not dependent on a small cluster of extremely premature infants at the lower tail of the gestational age distribution but was stronger $(r=-0 \cdot 23)$ when the six women who delivered between 28 and 32 weeks' gestation were excluded. In multiple regression analysis, with gestational age as the dependent variable, the association with albumin: creatinine ratio was independent of maternal age; ethnic origin; height, weight, and blood pressure at first visit; cigarette smoking; and gestational age at booking (partial $r=-0 \cdot 15$ ). The proportion of preterm births (delivery before 37 completed weeks' gestation) increased from the first to the fourth quartile of albumin:creatinine (table). No relation between

Distribution of preterm births by quartile of distribution of albumin: creatinine ratio

\begin{tabular}{lcc}
\hline Quartile & No of women & No (\%) with preterm birth \\
\hline First $(0.03$ to 0.3$)$ & 59 & $5(8)$ \\
Second $(0.35$ to 0.82$)$ & 58 & $8(14)$ \\
Third $(0.63$ to 1.12$)$ & 60 & $8(13)$ \\
Fourth $(1.13$ to 8.62$)$ & 56 & $14(25)$
\end{tabular}

$x^{2}$ test for trend $=5 \cdot 8, p=0.02$. urinary creatinine concentration and gestational age at delivery was observed $(r=-0.001)$.

\section{Comment}

We have found evidence of an association between urinary microalbumin excretion at the first antenatal visit and gestational age at delivery. This was a marginally significant result that emerged in exploratory analyses of several possible associations and our findings need to be replicated. However, the association was observed across the range of gestational ages at delivery and was not lessened in multiple regression analysis

Possible mechanisms underlying this finding are unclear. The association of microalbuminuria with vascular endothelial dysfunction ${ }^{4}$ may be relevant, since inflammatory and vasculitic changes in the placenta are seen in preterm birth. ${ }^{5}$ This observation (if confirmed) has important implications for work on the cause and prevention of preterm birth.

We thank the midwifery staff at Dudley Road Hospital, Birmingham for their support. Dr Goya Wannamethee and Mr Richard Morris of the department of public health and primary care, Royal Free Hospital, London, provided statistical advice. IJP was supported by the Wellcome Trust.

1 Lopez-Espinoza I, Dhar H, Humphreys S, Redman CWG. Urinary albumin excretion in pregnancy. Br 7 Obstet Gynaecol 1986;93:176-81

2 Rodriguez MH, Masaki DI, Mestman J, Kumar D, Rude R. Calcium/creatinin ratio and microalbumunuria in the prediction of pre-eclampsia. Am $\mathcal{F}$ Obstet Gynecol 1988;159:1452-5.

3 Cundy TF, Nixon D, Berkahn L, Baker J. Measuring the albumin excretion rate: agreement between methods and biological variability. Diabetic Med 1992;9:138-43.

4 Stehouwer CDA, Nauta JJP, Zeldenrust GC, Hackeng WHL, Donker AJM den Ottolander GJH. Urinary albumin excretion, cardiovascular disease, and endothelial dysfunction in non-insulin dependent diabetes mellitus. Lancet 1992;340:319-23.

5 Salafia CM, Vogel CA, Vintzileos AM, Bantham KF, Pezzullo J, Silberman I. Placental pathologic findings in preterm birth. Am $\mathcal{F}$ Obstet Gynecol 1991;165: 934-38.

(Accepted 22 fune 1993)
As a medical student death had never really intruded on me. Even doing a busy house job in the local casualty department did not prepare me for dealing with death at first hand. Most of the deaths were from severe trauma, or in people, often elderly, rushed in by ambulance in a moribund state. I never had to cope with the death of a patient whom I had known for any length of time. After my preregistration posts I moved into a paediatric house job and had the privilege of working for the late Professor A V Neale. He always emphasised the importance of talking to families; medical students sometimes felt that his preoccupation with family dynamics was rather boring and fanatical.

A 12 year old girl with leukaemia, usually fatal in those days, was admitted under his care. As house physician I dealt directly with the family, the registrar having a peripheral role at the time. I was not too worried about the possible death of this little girl as she was quite well and the family rarely mentioned this likely outcome.

I had come to form quite a close friendship with the family when she suddenly became very unwell with septicaemia and died. I was initially shocked and did not know what to do with the distressed parents or about my own feelings. No one had ever prepared me for this and the professor was unavailable. I drove the parents home and went into the house and sat with them. All I did was listen to their distress and look at photographs and possessions of the girl who had just died. I now know that I was possibly right in this instance just to listen and empathise, I am sure in a fumbling way. At the time I felt helpless, almost as upset as the parents, and had no idea what to do or say.
Later I went to the funeral. At the time I thought that this was a natural thing to do, but colleagues told me that this was wrong and I was getting too involved with my patients. A few weeks later the family came to see the professor and afterwards I was summoned to see himquite a daunting thing in those days. We sat and talked about the case and for the first time I was able to talk through ways of dealing with death with a respected paediatrician. The nicest thing he said to me was that he thought that I had handled it well and that the family was grateful for all I had done. A little later I received a letter of thanks and a small gift from the family, which made quite an impression on me.

This patient made me realise how badly we deal with death and how ill prepared many of us are to tackle it when we qualify. It also taught me the importance of visiting bereaved families in their homes, a practice which I still follow. Although I see bereaved parents in my office, I still prefer to visit them at home and in the past 10 years I have been involved in counselling families who have suffered a sudden death in infancy, again always in the home.

My early and subsequent experiences in dealing with death in childhood have made me include a discussion on dealing with the subject in the teaching of undergraduates and junior staff.

I still go to funerals.-ROGER HARRIs is a senior lecturer in child health at the Royal London Hospital

We are delighted to receive submissions of up to 600 words on $A$ paper (or patient or book) that changed my practice, $A$ memorable patient, The one message I would like to leave behind, or related topics. 